\title{
Sea Surface Temperature of the Bay of Bengal Derived from the TRMM Microwave Imager*,+
}

G S Bhat, G A Vecchi, S Gadgil. Journal of Atmospheric and Oceanic Technology. Boston: Aug 2004.Vol. 21, Iss. 8; pg. 1283, 8 pgs

Subjects:

Locations:

Author(s):

Article types:

Publication title:

Source Type:

ISSN/ISBN:

ProQuest document ID:

Text Word Count

Article URL:
Ocean temperature, Rainfall measurement, Ocean-atmosphere interaction, Radiometers, Meteorological satellites, Sensors

Bay of Bengal

G S Bhat, G A Vecchi, S Gadgil

Feature

Journal of Atmospheric and Oceanic Technology. Boston: Aug 2004. Vol. 21, Iss. 8; pg. 1283, 8 pgs

Periodical

07390572

687008331

4662

http://gateway.proquest.com/openurl?url_ver=Z39.88-2004\&res_ dat=xri:pqd\&rft_val_fmt=info:ofi/fmt:kev:mtx:journal\&genre=a rticle\&rft_dat=xri:pqd:did=000000687008331\&svc_dat=xri:pqil: fmt=text\&req_dat=xri:pqil:pq_clntid=58531

\section{Abstract (Article Summary)}

The Tropical Rainfall Measuring Mission (TRMM) Microwave Imager (TMI) with the capability of measuring sea surface temperature (SST) in the presence of clouds, has been providing an unprecedented view of tropical basin-scale SST variability. In this paper, an assessment of the accuracy of the SST derived from TMI over the Bay of Bengal using in situ data collected from moored buoys and research ships, is presented. The authors find that TMI captures the evolution of the SST of the bay on seasonal time scales with reasonable accuracy. The mean difference between the SST from TMI and buoys is less than $0.1^{\circ} \mathrm{C}$, and the rms difference is about $0.6^{\circ} \mathrm{C}$. The time scales of the intraseasonal variation of the TMI SST are realistic. However, the amplitude of the SST variation on the intraseasonal scale is overestimated by a factor of about 1.3 when compared to buoy data. It is observed that the SST derived from TMI tends to be lower during periods with deep convection or winds stronger than $10 \mathrm{~m} \mathrm{~s}^{\wedge}$ sup $-1^{\wedge}$, or both. There is better agreement during weak conditions of convection/wind. This leads to a cold bias during convectively active periods when running average SST time series are constructed from SSTs retrieved from the TMI. [PUBLICATION ABSTRACT]

Full Text (4662 words)

Copyright American Meteorological Society Aug 2004

[Headnote]

ABSTRACT

The Tropical Rainfall Measuring Mission (TRMM) Microwave Imager (TMI) with the capability of measuring sea surface temperature (SST) in the presence of clouds, has been providing an unprecedented view of tropical basin-scale SST variability. In this paper, an assessment of the accuracy 
of the SST derived from TMI over the Bay of Bengal using in situ data collected from moored buoys and research ships, is presented. The authors find that TMI captures the evolution of the SST of the bay on seasonal time scales with reasonable accuracy. The mean difference between the SST from TMI and buoys is less than $0.1^{\circ} \mathrm{C}$, and the rms difference is about $0.6^{\circ} \mathrm{C}$. The time scales of the intraseasonal variation of the TMI SST are realistic. However, the amplitude of the SST variation on the intraseasonal scale is overestimated by a factor of about 1.3 when compared to buoy data. It is observed that the SST derived from TMI tends to be lower during periods with deep convection or winds stronger than $10 \mathrm{~m}$ $\mathrm{s}^{\wedge} \sup -1^{\wedge}$, or both. There is better agreement during weak conditions of convection/wind. This leads to a cold bias during convectively active periods when running average SST time series are constructed from SSTs retrieved from the TMI.

\section{Introduction}

The Indian summer monsoon is an important phenomenon in the tropical atmosphere. It has been recognized for a long time that conditions over the oceans surrounding the Indian subcontinent play a major role in the genesis and propagation of the monsoon systems. However, advances in understanding how the ocean and the atmosphere interact over the north Indian Ocean on intraseasonal time scales during the monsoon are limited by the lack of research quality data in the region. Sea surface temperature (SST) is considered to be one of the most important variables for deep atmospheric convection over the tropical oceans (Bjerknes 1969; Gadgil et al. 1984; Graham and Barnett 1987; Bony et al. 1997a,b, etc.). The Reynolds SST (additional information available online at http://www.cdc.noaa.gov) was the main data source available to researchers until recently, providing weekly SSTs that could be used for the study of intraseasonal variations. In 1997 a moored buoy program was started in India by the National Institute of Ocean Technology, Chennai, and buoys were deployed in the Bay of Bengal and Arabian Sea (Premkumar et al. 2000). Figure 1 compares the temporal variations observed in (daily) buoy SST with the Reynolds weekly SST for the northern Bay of Bengal for the 1998 monsoon period. It is observed from Fig. 1 that the Reynolds SST during July-August shows only a mildly decreasing temporal trend. On the contrary, the buoy SST shows fluctuations in amplitude from $1.5^{\circ}$ to $2^{\circ} \mathrm{C}$ range on a time scale of about 2 weeks, and these fluctuations are closely associated with the changes in the outgoing longwave radiation (OLR) and wind (Premkumar et al. 2000). The absolute value of SST is important because the relationship between SST and deep convection is highly nonlinear with convection increasing rapidly with SST around $28.5^{\circ} \mathrm{C}$ (e.g., Waliser et al. 1993; Bhat et al. 1996). Therefore, the implications of the variations exhibited by the two SSTs in Fig. 1 are very different for deep convection and ocean-atmosphere coupling on intraseasonal time scales.

While buoys provide in situ observations that help in understanding the intraseasonal oscillations, their spatial coverage is limited and vast regions of the ocean remain data void. Further, the temporal continuity in buoy data is constrained by the degradation of sensor performance due to the corrosive marine conditions, damage to buoys, and pilferage. Satellites make possible continuous monitoring of the vast oceanic areas over which the convective systems are generated. In recent years there have been improvements in the remote sensing of the earth-atmosphere system. Therefore, there is a need to explore if the SSTs derived from satellite observations have reached a stage that permit studies of intraseasonal variations in the north Indian Ocean within the monsoon season.

A brief summary of the history of satellite-derived SSTs can be found in Wentz et al. (2000). Advanced Very High Resolution Radiometer (AVHRR) sensors flying aboard the National Oceanographie and Atmospheric Administration (NOAA) satellites, using measurements in the infrared bands, have been providing high spatial resolution SST data for more than two decades. One of the main limitations of the AVHRR sensor is that SST retrieval cannot be done when clouds are present. During the convective season, clouds are frequently present and, thus, render the region data sparse for SST derived from the AVHRR. Microwave sensing overcomes the cloud 
problem, and microwave radiometers were first operated in 1978 aboard a NOAA satellite. Initially this technique suffered from a poor calibration system. Microwave radiometers launched in the 1980s and 1990s, such as the Special Sensor Microwave Imager (SSM/I), used an improved calibration system but lacked the low-frequency channels needed to retrieve SST accurately (Wentz et al. 2000). These problems were overcome in the Tropical Rainfall Measuring Mission (TRMM) satellite launched in November 1997. The TRMM Microwave Imager (TMI) measures electromagnetic radiation emitted by the ocean-atmosphere system at 10.7, 19.4, 21.3, 37, and 85 $\mathrm{GHz}$ (e.g., Halpern et al. 2001, p. 4). The primary frequency for SST retrieval is $10.7 \mathrm{GHz}$ where atmospheric attenuation is small with $97 \%$ of the sea surface radiation reaching the top of the atmosphere. Using 19.4-, 21.3-, and 37-GHz radiances, the algorithm estimates the residual 3\% attenuation due to oxygen, water vapor, and clouds. Horizontal to vertical polarization ratios of radiances are used to estimate the sea surface roughness. The norizontal resolution of the SST retrieval is limited by the ratio of the radiation wavelength to the antenna diameter and by the satellite altitude. The TMI sensor's SST resolution is about $50 \mathrm{~km}$ (Wentz et al. 2000), but data are made available at $0.25^{\circ} \times 0.25^{\circ}$ resolution (Halpern et al. 2001, p. 4).

The TMI is the first satellite sensor capable of accurate measurements of SST in the presence of clouds. Comparison of TMI SSTs with SSTs measured with buoys and ships has shown good agreement in the mean and rms differences of about $0.6^{\circ} \mathrm{C}$ (Wentz et al. 2000). TMI SST is already providing an unprecedented view of tropical basin-scale SST variability during the convective season. It has been used to explore air-sea coupling in the Pacific Ocean tropical instability wave region (e.g., Chelton et al. 2001; Hashizume et al. 2001), and to explore the evolution of Indian Ocean SST on subseasonal time scales (Harrison and Vecchi 2001; Vecchi and Harrison 2002). Vecchi and Harrison (2002) studied the subseasonal evolution of the TMI SST in the bay during recent southwest monsoons, and found large-amplitude $\left(1^{\circ}-2^{\circ} \mathrm{C}\right)$ basin-scale subseasonal variability.

Thus, TMI SST holds promise for the north Indian Ocean also. TMI estimates the SST by measuring radiance emitted from the sea surface, and in situ data from the Pacific and Atlantic Oceans have been used to tune the SST retrieval algorithm (Wentz et al. 2000). There are important differences between the north Indian Ocean (during the monsoon) and other tropical ocean basins. The surface winds are often stronger than $10 \mathrm{~m} \mathrm{~s}$ sup $-1^{\wedge}$ over the north Indian Ocean when the monsoon is active. Further, in the north Bay of Bengal the surface salinity shows a large annual cycle with higher values ( $~ 33 \mathrm{psu}$ ) during spring and early summer, and lower values (-29 psu) during the monsoon and post-monsoon seasons [Bhat et al. (2001) and references therein]. These factors could affect the SST retrieved from the satellite measurements by influencing the surface emissivity. A study comparing TMI SST with in situ data in the north Indian Ocean is missing, and the present work is aimed at filling this gap.

Here, we present a comparison of the SST derived from the TMI with that measured by moored buoys in the bay during 1998-99 and the observations from ships made during the Bay of Bengal Monsoon Experiment (BOBMEX) in July-August 1999 (Bhat et al. 2001). We also explore possible causes for the difference between buoy and TMI SST with the use of the atmospheric and oceanic data collected during BOBMEX.

\section{Data}

The TRMM is a non-sun-synchronous satellite. We utilize the SST derived from measurements during the ascending as well as descending passes over the region. In the present study, the TMI SST version 3 has been used (data available online at http://www.ssmi.com/). An average over four grids surrounding the ship or buoy position is taken in the present study so as to be consistent with the TMI sensor resolution. The locations of the two buoys and the ships deployed in the Bay 
of Bengal are shown in Fig. 2 and the dates on which data are available are given in Table 1. (One of the main reasons for the gaps in the buoy data was the pilferage of the buoys, requiring deployment of new buoys or a new set of sensors during this period.) In the buoys, SST is measured by a platinum resistance thermometer placed at $2.2 \mathrm{~m}$ below the surface. Buoy data sampling interval is $3 \mathrm{~h}$. SST measured from ships is the bucket SST that corresponds to the water temperature at a depth of about $0.50 \mathrm{~m}$. The temperature sensors used on board the ship, ORV Sugar Kanya (SK), were calibrated in the laboratory at the Indian Institute of Science in Bangalore, using a constant temperature bath and ice water reference point. The sensors installed in the buoys have been calibrated in the laboratory at the National Institute of Ocean Technology in Chennai. After each buoy deployment, buoy data are compared with those simultaneously measured from the ship to ensure that the performance of the sensors on the buoy were not altered during deployment. The bucket thermometer used onboard SK was manufactured by T. F. and Company, Germany, and that used onboard INS Sagardhwani (SD) was a local make. The uncertainty in the bucket SST ( $\mathrm{Hg}$ in glass thermometer) is $0.25^{\circ} \mathrm{C}$ and the accuracy of buoy SST is $0.1^{\circ} \mathrm{C}$.

\section{Comparison of TMI SST with buoy and ship measurements}

\section{a. Comparison of buoy and ship SST}

Intercomparison experiments were carried out at the DS3 location for about $12 \mathrm{~h}$ each at the start (18-19 July) and toward the end (27 August) of BOBMEX (Bhat et al. 2001). Figure 3a compares the SST and wind speed measured from ships and DS3 buoy. It is observed from Fig. 3a that, except for one occasion on 27 August, the agreement between SK and buoy SSTs is excellent and well within the measurement uncertainties. The SD (bucket) SST tends to be slightly lower, but the differences are within the measurement errors. The ship wind speed shown in Fig. 3a was measured by a sonic anemometer mounted on an 8-m-long boom at a mean height of $11 \mathrm{~m}$ above the sea surface and has been corrected for ship motion. On the buoy, a cup anemometer was fixed at a height of $3.2 \mathrm{~m}$ above the sea surface. (The correction for the measurement height difference has not been applied in the winds shown.) It is observed from the lowest panel in Fig. 3a that the wind speed measured from the ship and buoy compare well, and the average wind speeds were in an 8-12 $\mathrm{m} \mathrm{s}^{\wedge}$ sup $-1^{\wedge}$ range during the 27 August intercomparison experiment. Wind speeds during the intercomparison experiment on 18-19 July were comparable to those on 27 August. With high wind speeds and a rough sea state during both intercomparison experiments, the top layer of the ocean was well mixed and the difference in the temperature between bucket SST level and buoy SST level can be ignored. The good agreement between ship and buoy SSTs observed in Fig. 3a gives confidence that the SST data from buoys and ships are accurate to the respective uncertainties stated above.

In Fig. 3b, daily average SSTs from the buoys and ships are shown. In the north bay, the ship and buoy were more than $100 \mathrm{~km}$ apart, and the two SSTs are shown together to reveal the typical spatial variations that were present during 1999 summer monsoon. It is observed from Fig. 3b that the differences between two SSTs are less than $0.5^{\circ} \mathrm{C}$, and, except on a couple of occasions (the atmosphere was convectively active when this happened), the SK and DS4 buoy SSTs show similar temporal trends. In the central bay, ship and buoy SSTs confirm the intercomparison experiment observations.

\section{b. Comparison of collocated SSTs}

The scatterplot of buoy SST versus TMI SST for all collocated data during 1998 and 1999 are shown in Fig. 4. If the buoy data are available within half an hour from the TRMM satellite pass over the grid, then the data are considered collocated here. For the DS4 buoy location, 86 
collocated data points are available, and the mean difference between buoy SST and TMI SST is less than $0.1^{\circ} \mathrm{C}$ (buoy SST is warmer) and the rms difference is $0.7^{\circ} \mathrm{C}$. At the DS3 location, 95 collocated data are available, and the mean difference between buoy SST and TMI SST is $0.1^{\circ} \mathrm{C}$ (buoy SST is warmer) and the rms difference is $0.5^{\circ} \mathrm{C}$. The present values of rms differences are comparable to $0.6^{\circ} \mathrm{C}$ observed between buoy SST and TMI SST over the Pacific Ocean (Wentz et al. 2000).

\section{c. Seasonal and subseasonal SST variations}

The variation of the 7-day running average TMI and buoy SSTs over the central bay during 1998 are shown in Fig. 5. The warming of the ocean from about $27^{\circ} \mathrm{C}$ in January to more than $31^{\circ} \mathrm{C}$ in May is seen in the buoy data. June-September is the peak monsoon period, and subseasonal oscillations in SST are clearly seen. The TMI SST captures the seasonal SST evolution in good agreement with the buoy SST; however, the amplitudes of the variations on subseasonal time scales are larger in the TMI SST compared to that of the buoy. The amplitude of SST variation measured by the buoy is about $1^{\circ} \mathrm{OC}$, while the TMI SST shows variation between $1^{\circ}$ and $1.5^{\circ} \mathrm{C}$. The spectra of the buoy and TMI SSTs for the central bay are shown in Fig. 6 . These spectra are based on 256 samples of the 7-day running average SST covering the period January-October1998. The time period shown in Fig. 6 is limited to 10-64 days to omit the parts of the spectrum possibly influenced by the 7-day averaging and the relatively short duration of the time series. Prominent peaks around 32-and 42-day periods are seen in both TMI and buoy SSTs. Therefore, $\mathrm{TMI}$ is able to capture the period of subseasonal (intraseasonal) variations of the monsoon on a 20-60-day time scale well, but overestimates the amplitude of SST variation by a factor of about 1.3. Also, we see a slightly larger amplitude of the fluctuations in the TMI SST at shorter time scales of $10-20$ days.

\section{Discussion}

Considering the complexities involved in retrieving SST from satellite measurements, the good agreement between buoy SST and TMI SST with a mean difference of $0.1^{\circ} \mathrm{C}$ or less is truly remarkable. The scatter with rms value of about $0.6^{\circ} \mathrm{C}$ represents the inherent error in the SST retrieval by the TMI algorithm. We explore some factors that could lead to a larger difference than this using the detailed measurements made during BOBMEX.

The TMI SST corresponds to the temperature of the top $1 \mathrm{~mm}$ or so of the water, whereas the buoy SST is measured at $2.2 \mathrm{~m}$ below the surface. It has been suggested that the difference between the buoy/ship SST and TMI SST could partly be a manifestation of the variation of temperature with depth in the top few meters (e.g., Wentz et al. 2000). Since the TMI SST is retrieved from measurements of the radiance emitted by the sea surface, changes in the sea surface emissivity will influence the value of the TMISST. The sea surface roughness (which in turn depends on wind speed) and sea surface salinity (SSS) are among the factors that influence the sea surface emissivity. We attempt to assess whether either of these two factors, that is, the variation of temperature with depth and the variation of emissivity due to the variation of wind speed and surface salinity, could have led to the large difference between buoy and TMI SSTs.

Since the TMI sensor measures the temperature very near the surface (although not strictly the skin temperature), we can expect it to be influenced by factors such as the rate of evaporation, incident shortwave radiation, wind speed net longwave cooling, etc. At night the skin temperature is less than the bulk temperature because there is net energy loss from the surface. During the daytime, if the clear-sky solar insolation is high and rate of evaporation small, we expect the skin temperature to be higher than the bulk temperature. During periods of high insolation and low winds, the skin temperature is observed to be about $1.5^{\circ} \mathrm{C}$ warmer than the bulk or subsurface 
temperature, whereas it is cooler by about $0.2^{\circ} \mathrm{C}$ at wind speeds exceeding $6 \mathrm{~m} \mathrm{~s} \mathrm{~s}^{\wedge} \mathrm{sup}-1^{\wedge}$ (Donlon et al. 1999). Hence, if skin versus bulk temperature difference contributed significantly to the differences between the buoy and TMI SSTs, then we may expect [Delta]T (buoy SST minus TMI SST) to depend on the local standard time (LST) and wind speed.

We examine the hypothesis by plotting [Delta]T against LST and wind speed. In Fig. 7a, [Delta]T is plotted against LST. Preference for the sign of [Delta]T to depend on LST is not observed in this figure. One aspect evident in Fig. 7a is that, when buoy and TMI SSTs differ by more than I0C, then it is more likely that [Delta]T is positive (TMI SST is less than buoy SST). In Fig. 7 [Delta]T is plotted against wind speed. Wind data are not available for all collocated SST data and, hence, this plot has a lesser number of points. Depending on the satellite pass time, the data are classified into day (1000-1600 LST), night (2100-0600 LST), and rest (0600-0900 and 1600-2100 LST) categories in Fig. 7b. There are very few data points belonging to day category for wind speeds less than $4 \mathrm{~m} \mathrm{~s}^{\wedge}$ sup $-1^{\wedge}$ where the heating due to solar radiation is expected to be most prominent (e.g., Donlon et al. 2002). In the 4-8 $\mathrm{m} \mathrm{s} \mathrm{s}^{\wedge}$ sup $-1^{\wedge}$ wind speed range, there is a larger number of data points but no clear dependence either on wind speed or on time of day.

To explore if the SST derived from the TMI shows any association with the wind speed and surface salinity (SSS), which influence the surface emissivity, we have plotted SSTs along with hourly rainfall, surface wind speed, SSS, and daily Indian Satellite (INSAT) outgoing longwave radiation during BOBMEX in Figs. 8a-c. [At DS4 (Fig. 8b), rainfall and SSS are not available, and OLR is used as proxy for convection.] Certain features are common in Figs. 8a-c (the short duration of time series does not permit confirming these with a statistical significance test). It is observed from Fig. 8a (north bay) that TMI SSTs are not reported when rainfall/convection is intense. The TMI algorithm does not give SST values when it senses precipitating clouds, and the results in Fig. 8a are consistent with this. (The rains on 20 and 22 August were from short-lived convective clouds and not associated with organized convective systems.) There are many occasions when TMI SST is more than $0.6^{\circ} \mathrm{C}$ colder than buoy/ship SST, and these events are associated with decreasing values of OLR (i.e., increasing cloudiness) or wind speeds above $10 \mathrm{~m} \mathrm{~s}$ sup $-1^{\wedge}$ or both. TMI and buoy/ship SSTs are in good agreement with each other when OLR values were increasing or wind speeds were below $10 \mathrm{~m} \mathrm{~s} \wedge$ sup $-1^{\wedge}$. The role of SSS on TMI SST, if any, is not clear from Fig. 8. (SSS was measured by a CTD and the minimum depth of SSS measurements was $1 \mathrm{~m}$. Existence of a freshwater lens at the top, if any, was not explored during BOBMEX.) For example, in the north bay, SSS decreased from around 33 psu on 27 July to less than 29 psu on 3 August and remained low therafter. This decrease in SSS is related to the arrival of a freshwater plume from the northwest in the first week of August at the ship/buoy location (Vinayachandran et al. 2002). After this event also, TMI and buoy SSTs continued to be in good agreement when winds decreased and OLR increased (19-23 August) in the north bay. Thus, the negative bias of the TMI SST could be associated with cloud cover, which is invariably present during the convectively active phase (with precipitation, if any, being less than the threshold in the TRMM algorithm) or higher wind speeds that accompany the convection.

It should be noted that during the rainfall events the TMI SST data are missing. For certain purposes, it is necessary to have continuous data in time, and a running average needs to be taken. A 7-day running average gives continuous TMI SST data. Now the largest errors in the TMT SST often appear either before or after rain events with the TMI SST being less than buoy SST (Fig. 8). Thus, when a running average around a convective period is taken, few SST data points having a cold bias dominate the average and fill the time gaps. Whereas in the scatterplots, the number of data points belonging to low wind/nonconvective periods outnumber those belonging to convective periods (e.g., Fig. 4), and the agreement between buoy and TMI SSTs looks excellent. Thus, the scatterplot (Fig. 4) and running average plot (Fig. 5) convey somewhat different impressions regarding the agreement between buoy and TMI SST values. There is a need to explore if this problem can be overcome while generating continuous time series of the TMI SST. 


\section{Conclusions}

Comparison of TMI and in situ SSTs for the Bay of Bengal in the north Indian Ocean has been carried out. Important observations from the study are as follows.

(i) TMI SST captures reasonably well the evolution of the seasonal mean SST field over the bay. The difference between the buoy and TMI SST is less than $0.1^{\circ} \mathrm{C}$ in the mean (buoy warmer) and the rms difference is $0.5^{\circ} \mathrm{C}$ in the central bay and $0.7^{\circ} \mathrm{C}$ in the north bay.

(ii) On the subseasonal time scale, there is a bias in the TMI SST toward lower values during convective phases; whereas the SST values from the TMI and buoy are close in the absence of convection.

(iii) TMI appears to have about $160 \%$ of the subseasonal energy of the buoy SST.

(iv) The negative bias of TMI SST could be associated with cloud cover or higher wind speeds, which accompany the convectively active phase.

More work is needed to understand the source of bias during the convective season and to develop methods for its elimination. When this is done, the TMI SST dataset will provide an invaluable tool in the development of our understanding of air-sea interactions in the Bay of Bengal during the monsoon.

Acknowledgments. This work was partially supported by a grant from Department of Science and Technology, New Delhi, and the Indian Space Research Organization. Several Indian Government agencies supported BOBMEX. We thank all the agencies involved in BOBMEX. We thank the National Institute of Ocean Technology, Chennai, for providing the buoy data and India Meteorology Department for the INSAT data. GAV would like to thank D. E. Harrison and S. Ilcane, and was supported by NASA's Physical Oceanography Program, by JISAO under NOAA Cooperative Agreement NA67RJ0155, and through the UW/PMEL Hayes Center. TMI data are produced by Remote Sensing Systems and sponsored, in part, by NASA's Earth Science Information Partnerships, and by the NOAA NASA Pathfinder Program for early EOS products (principal investigator: Frank Wentz). The Reynolds SST data were obtained from the NOAACIRES Climate Diagnostics Center, Boulder, Colorado, from their Web site (online at http://www.cdc.noaa.gov/).

\section{[Footnote]}

${ }^{*}$ National Oceanic and Atmospheric Administration/Pacific Marine Environmental Laboratory Contribution Number 2564.

+ National Oceanic and Atmospheric Administration/Office of Oceanic and Atmospheric Headquarters and Office of Global Programs Contribution Number 979.

\section{[Reference]}

REFERENCES

Bhat, G. S., J. Srinivasan, and S. Gadgil, 1996: Tropical deep convection, convective available potential energy and sea surface temperature. J. Meteor. Soc. Japan, 74, 155-166.

, and Coauthors, 2001: BOBMEX: The Bay of Bengal Monsoon Experiment. Bull. Amer. Meteor. Soc., 82, 2217-2243.

Bjerknes, J., 1969: Atmospheric teleconnections from the equatorial Pacific. Mon. Wea. Rev., 97, 163172.

Bony S., K. M. Lau, and Y. C. Sud, 1997a: Sea surface temperature and large scale circulation influences on torpical greenhouse effect and cloud radiative forcing. J. Climate, 10, 2055-2077.

, Y. Sud, K. M. Lau, J. Susskind, and S. Saha, 1997b: Comparison and satellite assessment of 
NASA/DAO and NCEP-NCAR reanalyses over tropical ocean: Atmospheric hydrology and radiation. J. Climate, 10, 1441-1462.

Chelton, D. B., and Coauthors, 2001: Observations of coupling between surface wind stress and sea surface temperature in the eastern tropical Pacific. J. Climate, 14, 1479-1498.

Donlon, C. J., T. J. Nightingale, T. Sheasby, J. Turner, I. S. Robinson, and W. J. Emery, 1999: Implications of the oceanic thermal skin temperature deviation at high wind speed. Geophys. Res. Lett., 26, 2505-2508.

, P. Minnett, C. Gentemann, T. J. Nightingale, 1. J. Barton, B. Ward, and J. Murray, 2002: Toward improved validation of satellite sea surface measurements for climate research. J. Climate, 15, 353-369. Gadgil, S., P. V. Joseph, and N. V. Joshi, 1984: Ocean-atmosphere coupling over monsoon regions. Nature, 312, 141-143.

Graham, N. E., and T. P. Barnett, 1987: Sea surface temperature, surface wind divergence, and convection over tropical oceans. Science, 238, 657-659.

Halpern, D., P. M. Woiceshyn, V. Zlotnicki, O. B. Brown, G. C. Feldman, M. H. Freilich, F. J. Wentz, and C. Gentemann, 2001: An Atlas of Monthly Mean Distributions of SSMI Surface Wind Speed, AVHRR Sea Surface Temperature, TMI Sea Surface Temperature, AMI Surface Wind Velocity, SeaWiFS Chlorophylla, and TOPEX/POSEIDON Sea Surface Topography during 1999. NASA Jet Propulsion Laboratory, California Institute of Technology, Publication 01-01, 102 pp.

Harrison, D. E., and G. A. Vecchi, 2001: January 1999 Indian Ocean cooling event. Geophys. Res. Lett., 28, 3717-3720.

Hashizume, H., S.-P. Xie, W. T. Liu, and K. Takeuchi, 2001: Local and remote atmospheric response to tropical instability waves: A global view from space../. Geophys. Res., 106 (DIO), 10 173-10 185.

Premkumar, K., M. Ravichandran, S. R. Kalsi, D. Sengupta, and S. Gadgil, 2000: First results from a new observational system over the Indian seas. Curr. Sci., 78, 323-331.

Vecchi, G. A., and D. E. Harrison, 2002: Monsoon breaks and subseasonal sea surface temperature variability in the Bay of Bengal. J. Climate, 15, 1485-1493.

Vinayachandran, P. N., V. S. N. Murty, and V. Ramesh Babu, 2002: Observations of barrier layer formation in the Bay of Bengal during summer monsoon. J. Geophys. Res., 107, 8018, doi: 10.1029/2001JC000831.

Waliser, D. A., N. E. Graham, and C. Gautier, 1993: Comparison of the highly reflective cloud and outgoing longwave radiation datasets for use in estimating tropical deep convection. J. Climate, 6, 331353.

Wentz, F. J., C. Gentemann, D. Smith, and D. Chelton, 2000: Satellite measurements of sea surface temperature through clouds. Science, $288,847-850$.

\section{[Author Affiliation]}

G. S. BHAT

Centre for Atmospheric and Oceanic Sciences, Indian Institute of Science, Bangalore, India G. A. VECCHI

Joint Institute for the Study of the Atmosphere and Oceans, University of Washington, Seattle, Washington

S. GADGIL

Centre for Atmospheric and Oceanic Sciences, India Institute of Science, Bangalore, India

(Manuscript received 2 April 2003, in final form 11 November 2003)

\section{[Author Affiliation]}

Corresponding author address: Prof. G. S. Bhat, Centre for Atmospheric and Oceanic Sciences, Indian Institute of Science, Bangalore 560 012, India.

E-mail: bhat@caos.iisc.ernet.in

Copyright @ 2004 ProQuest Information and Learning Company. All rights reserved. Terms and Conditions

Text-only interface 